responses in discriminative learning. In N. R. Ellis (Ed.), International review of research in mental retardation. Vol. 2. New York: Academic Press, 1966.

Shepp, B. E. \& Turrisi, F. D. Effects of overtraining on the acquisition of intradimensional and extradimensional shifts. Journal of Experimental Psychology, 1969, 82, 46-51.

Sutherland, N. S. \& Andelman, L. Effects of overtraining on intra- and extra-dimensional shifts. Psychonomic Science, $1969,15,253-254$.

Sutherland, N. S. \& Mackintosh, N. J. Mechanisms of Animal Discrimination Learning. New York: Academic Press, 1971.

Thomas, D. R., Freeman, F., Svinicki, J. G., Burr, D. E. S. \& Lyons, J. Effects of extradimensional training on stimulus generalization. Journal of Experimental Psychology Monograph, 1970, 83, No. 1, Part 2.

Turrisi, F. D., Shepp, B. E., \& Eimas, P. D. Intra- and extra-dimensional shifts with constant- and variable-irrelevant dimensions in the rat. Psychonomic Science, 1969, 14, 19-20.

Waller, T. G. Effect of irrelevant cues on discrimination acquisition and transfer in rats. Journal of Comparative and Physiological Psychology, 1970, 73, 477-480.

Waller, T. G Facilitation of an extradimensional shift with overtraining in rats. Psychonomic Science, 1970, 20, 172-174.

waller, T. G. The effect of overtraining on two extradimensional shifts in rats. Psychonomic Science, 1971, 23, 123-124.

Waller, T. G. The effect of overtraining on a visual discrimination on transfer to a spatial discrimination. Animal Learning and Behavior, 1973, 1, 65-67.

Warren, J. M. \& McGonigle, B. Effects of differential and nondifferential reinforcement on generalization test performance by cats. Journal of Comparative and Physiological Psychology, 1969, 69, 709-712.

(Received for publication November 8, 1974.)

\title{
Masking effectiveness of disks varying in duration and in number of internal segments
}

\author{
WILLIAM N. DEMBER, BRENDA BRYANT, and JOHN CHAMBERS \\ University of Cincinnati, Cincinnati, Ohio 45221
}

\begin{abstract}
When used as target stimuli, disks become both less detectable and less susceptible to backward masking with an increase in the number of black and white pie-shaped segments of which they are composed. The present study investigated the effectiveness of such stimuli in masking letter targets. Four values of number of mask segments $(4,8,12,16)$ and four mask durations $(5,10,15,20 \mathrm{msec})$ were employed in a backward masking paradigm. The data (in the form of percent correct letter identification) revealed significant effects of both variables and no interaction between them. Masking effectiveness increased both with increasing duration and increasing number of mask segments. The results refute an hypothesis based on the characterization of short-duration, multisegmented disks as "weak figures" and support either of two alternate hypotheses, one that refers to "self-generated inhibition" and the other to "contour confusion."
\end{abstract}

Research for this paper was supported by Grant GB 33621 from the National Science Foundation. Reprints should be requested from William N. Dember, Department of Psychology, University of Cincinnati, Cincinnati, Ohio 45221.
Visual backward masking involves the effect, usually inhibitory, of one visual stimulus (the mask) on the perception of an immediately preceding visual stimulus 
(the target). A great deal of research has been done to identify the variables which affect backward masking, and where possible to establish functional relations among those variables and indices of extent of masking. Some of these relationships have been singled out for special attention by theorists attempting to construct models of the masking process; among recently proposed models temporal relationships have played a central role, particularly the relation between extent of masking and the duration of the interval separating target and mask onsets (see reviews and theoretical articles by Kahneman, 1968; Lefton, 1972; Raab, 1963; Weisstein, 1968; for further details).

Of relatively little concern in contemporary masking models are configurational variables of the sort that Heinz Werner, one of the seminal researchers in this area, found so intriguing (see Werner, 1935). Such variables (e.g., target size and shape, mask size and shape, target-mask similarity, target-mask proximity, presence or absence of internal contours in target and mask) have not gone unstudied; however, thier heuristic value in the construction of masking models has diminished in importance since Werner treated masking as essentially a contour-formation phenomenon.

The present experiment is one of a series which followed up a conclusion emerging from Werner's classic studies: targets containing internal contours are less susceptible to backward masking than are homogeneous targets. The basic stimulus pattern which Werner employed consisted of a black disk-shaped target and a black, ring-shaped mask. Under optimal conditions, the subjects reported the ring-center to appear empty, even though that location had just been occupied by a black disk. In much of our research, a dual-ring mask was employed to accommodate a spatial forced-choice indicator response; that is, the target was presented within one of two adjacent rings, and the subject's task was to indicate, by saying "left" or "right," the location of the target.

Using such a dual-ring mask and a forced-choice indicator response, Sherrick \& Dember (1970) tested the hypothesis that homogeneous targets were more susceptible to masking than were targets with internal contours. In that experiment, the internally-contoured targets were black on one side of the diameter and white on the other. Such targets did prove, as predicted, less easily masked than homogeneous black targets. Subsequent experiments (Cox \& Dember, 1970; Dember, Mathews, \& Stefl, 1973; Dember \& Stefl, 1972; Ellis \& Dember, 1971) were conducted to determine whether a functional relation existed between number of internal target contours and target maskability. In addition, a control condition was included to assess the detectability of multicontoured targets in the absence of a masking stimulus. The disk-shaped targets contained varying numbers of alternating black and white pie-shaped segments; a homogeneous disk was also included. Three findings emerged clearly from those experiments: (1) As number of segments increased, target detectability decreased under the nonmasking, "control" condition; (2) relative to their nonmasking detectability values, targets became increasingly difficult to mask as number of segments increased, up to a limiting number of target segments somewhere between 16 and 32 ; (3) some multisegmented targets were not maskable and some were actually increased in detectability by the masking stimulus.

Thus, whether a conventional backward masking paradigm yielded inhibition, no effect, or even enhanced target detectability turned out to be critically dependent on configurational properties of the target stimulus. That finding casts serious doubt on the adequacy of any masking model which ignores configurational variables. It also leads to some interesting questions about the exact nature of the configurational variable which generates those anomalous results and about possible underlying mechanisms that would make certain targets both difficult to detect and difficult to mask.

The present experiment is an attempt to learn more about the properties of these paradoxical stimuli. In particular, it asks how these stimuli function in the role, not of targets, but of masks, at different values of mask duration, and with letters of the alphabet as target stimuli.

There are at least three ways of considering the potential masking effectiveness of multisegmented stimuli: (1) Our previous research shows that as targets under nonmasking conditions they are relatively difficult to detect; that is, they have longer duration thresholds than targets with few or no internal contours. Hence, when presented as short durations, multisegmented stimuli might be thought of as "weak figures" and as such might be expected to serve as relatively ineffective masking stimuli. However, at longer, above-threshold durations, multisegmented masking stimuli should not be at a disadvantage; indeed, by virture of their resistance to masking when serving as targets, there is reason to expect long-duration multisegmented disks to act as highly effective masking stimuli. (2) These multisegmented figures, when serving as targets, might be relatively difficult to detect because they generate considerable inhibition within themselves (Dember \& Stefl, 1972). This source of inhibition may simply be transferred to the target stimuli when these multisegmented disks serve as masks. The amount of inhibition imposed on the target stimuli from this source is not expected to interact with mask duration, although in general longer duration masks should produce greater masking effects. (3) Ignoring what is known, or speculated about these multisegmented disks from our previous experiments, one might make the same predictions as in (2) above simply by arguing that the greater the number of elements in a masking figure, the greater its masking effectiveness; this relation might be mediated by the confusion of the masking figure contours and the critical features of the target stimuli 
Table 1

Percentage Correct Letter Identification as a Function of Mask Duration and Number of Mask Segments

\begin{tabular}{cccccc}
\hline $\begin{array}{c}\text { Mask } \\
\text { Duration } \\
\text { (Msec) }\end{array}$ & \multicolumn{4}{c}{ Number of Segments } & \\
\cline { 2 - 5 } & 4 & 8 & 12 & 16 & Mean \\
\hline 5 & 71.7 & 49.1 & 40.0 & 20.0 & 45.2 \\
10 & 48.7 & 35.6 & 28.4 & 32.3 & 36.2 \\
15 & 43.1 & 24.1 & 21.9 & 22.7 & 28.0 \\
20 & 38.1 & 19.9 & 20.3 & 22.3 & 25.1 \\
Mean & 50.4 & 32.2 & 27.6 & 24.3 & \\
\hline
\end{tabular}

(see also Arand \& Dember, 1974).

To summarize, the "weak figure" interpretation predicts an interactive effect on masking between number of segments in the masking figure and mask duration, with multisegmented masks being less effective at short durations but more effective at long durations than masking figures with fewer segments. On the other hand, both the "self-generated inhibition" and the "contour confusion" interpretations predict greater effectiveness of the multisegmented masks at all mask durations.

\section{METHOD}

\section{Subjects}

Three male and four female college students, with normal or corrected-to-normal vision, served as paid subjects. They were trained on the task, and exposed 25 times to each experimental condition during 200 trials presented on each of the two days preceding the start of the experiment.

\section{Stimuli}

The target stimuli were the capital letters $\mathrm{D}$ and $\mathrm{O}$ drawn in black ink on a white background. The letters were $7.1 \mathrm{~mm}$ high, $6.0 \mathrm{~mm}$ wide, with a strip width of $1.5 \mathrm{~mm}$, corresponding respectively to $21.0,18.0$, and $4.5 \mathrm{~min}$ of arc. The masking stimuli were disks composed of $4,8,12$, or 16 alternating black and white pie-shaped segments. Disk diameter was $8 \mathrm{~mm}$ (23.5 min of arc).

\section{Design and Procedure}

Each subject was run on each of the 16 conditions generated by the four masking stimuli $(4,8,12,16$ segments) and four values of mask duration $(5,10,15$, or $20 \mathrm{msec})$. Each subject received a different random order of conditions. Two conditions were run per day on each of 8 days, with 100 trials per condition. There was a $10-\mathrm{min}$ rest period between conditions and a 5-min dark-adaptation period preceding each daily session. On half the trials, the target was the letter D and on half the letter $\mathrm{O}$, with target letter randomized over trials.

The stimuli were presented in a Scientific Prototype tachistoscope, Model GB. The two target stimuli were attached to a metal plate which could be moved with precision so as to assure that on each trial one of the target stimuli was exactly centered within the locus of the masking disk. Target and mask were presented in the center of the subject's fixation field.

After a ready signal from the experimenter, the subject. initiated the target-mask sequence by pressing a button. A complete trial consisted of the following events: fixation field; target stimulus; interstimulus interval; mask field; fixation field. Illumination in all fields was fixed at $10 \mathrm{fL}$. Target duration was fixed at $10 \mathrm{msec}$ and interstimulus interval at $50 \mathrm{msec}$. Mask duration varied as indicated. Viewing was monocular. The subject's task was to identify the target letter, guessing when necessary.

\section{RESULTS AND DISCUSSION}

For each condition, percent correct target identifciation $\left(\mathrm{P}_{\mathrm{o}}\right)$ was computed and corrected for guessing by the formula:

$$
P_{c}=\frac{P_{o}-.50}{.50}
$$

Mean $\mathbf{P}_{\mathbf{c}}$ over the seven subjects is given in Table 1 for each of the 16 conditions. A two-way repeated measures analysis of variance indicated that both main effects were significant $(\mathrm{p}<.01, \mathrm{df}=3 / 18)$. For mask duration, $\mathrm{F}=6.25$; for mask type (number of segments), $\mathrm{F}=$ 10.48. The interaction between mask duration and mask type was not significant.

The results for mask duration are as anticipated: masking effectiveness increased with increasing mask duration (see, for example, Alpern, 1953). The data also reveal increasing mask effectiveness with increasing number of segments in the masking figure. That result, which holds at short as well as long durations, clearly refutes the "weak figure" interpretation presented earlier. The results, instead, are consistent with the alternate hypotheses, one based on the notion of self-generated inhibition, the other on the simpler notion of target-mask contour confusion. Thus, the present data are consistent with the explanation of earlier results which alludes to self-generated inhibition, though they do not require such an account. Despite the orderliness of the present data, the strategy of using multisegmented disks as masking stimuli has unfortunately not increased our understanding of their peculiar properties when serving as target stimuli in a backward masking paradigm; for that to have occurred, the "weak figure" hypotheses would have to have been verified.

\section{REFERENCES}

Alpern, M. Metacontrast. Journal of the Optical Society of America. 1953. 43.646-657.

Arand, D., \& Dember, W. N. Masking effectiveness and number of segments in the masking ring. Bulletin of the Psychonomic Society, 1974, 3, 127-128.

Cox, S. I., \& Dember, W. N. Backward masking of visual targets with internal contours. Psychonomic Science, 1970, 19, 225-256.

Dember, W. N., Mathews, W. D., \& Stefl, M. Backward masking and enhancement of multisegmented visual targets. Bulletin of the Psychonomic Society, 1973, 1, 45-47.

Dember, W. N., \& Stefl, M. Backward enhancement? Science, $1972,175,93-95$.

Ellis, D., \& Dember, W. N. Backward masking of visual targets with internal contours: A replication. Psychonomic Science, $1971,22,91-92$.

Kahneman, D. Method, findings, and theory in studies of visual masking. Psychological Bulletin, 1968, 70, 404-425.

Lefton, L. A. Metacontrast A review: Psychonomic Monograph Supplements, 1972, 4, 245-255.

Raab, D. H. Backward masking. Psychological Bulletin, 1963, $60,118-129$.

Sherrick, M. F., \& Dember, W. N. Visual backward masking and the area-detection relation. Psychonomic Science, 1970, 19, 127-128.

Weisstein, N. A Rashevsky-Landahl neural net: Simulation of metacontrast. Psychological Review, 1968, 75, 494-521.

Werner, H. Studies on contour: I. Qualitative analyses. American Journal of Psychology, 1935, 47, 40-64.

(Received for publication December 12, 1974.) 